Greaves, Tom.

1994. Intellectual Property Rights for Indigenous Peoples, A Sourcebook. Society for Applied Anthropology.

Kemp, William and L. Brooke.

1995. Towards Information Self-Sufficiency: The Nunavik Inuit Gather Information of Ecology and Land Use. Cultural Survival Quarterly. Winter. pp. 25-28.

Morin-Labatut, G. and S. Akhtar.

1992. Traditional Environmental Knowledge: A Resource to Manage and Share. Development 4: 24-30.

Wolfe, J., C. Bechard, P. Cizek, D. Cole.

1992. Indigenous and Western Knowledge and Resource Management Systems. Rural Reportings, Native Canadian Issues Series, 1. University of Guelph. Ontario.

\title{
Ecological Identity: Becoming a Reflective Environmentalist, by Mitchell Thomashow. The Massachusetts Institute of Technology Press, 1995. 228 pp.
}

\author{
Reviewed by Caroline Pomeroy, Institute of Marine Sciences, \\ University of California, Santa Cruz.
}

Mitchell Thomashow's Ecological Identity: Becoming a Reflective Environmentalist is a thought-provoking, if at times overly personalized and moralistic, work focusing on the relationship between ecological identity and environmental action. Directed toward environmental professionals, teachers of environmental studies, and others who seek to "connect their inner voices with understanding of ecology, community, and citizenship," (p.xiii) Ecological Identity is offered as a sorcerous and guide for that process, termed "ecological identity work" (EIW). As Thomashow sees it, those who seek to make this connection face a fundamental tension between their sense of wonder about nature on the one hand, and their perception of threats to its well-being on the other. The challenge is to maintain, develop and share that sense of wonder while also conveying the importance and urgency of acting to address those threats. EIW entails "using the direct experience of nature as a framework for personal decisions, professional choices, political action, and spiritual inquiry" (p.xiii) to meet this challenge, and thereby benefit those who use this approach, society, and nature.

Thomashow presents ecological identity work in both practical and theoretical context. He provides anecdotes drawn from his own 20-year experience and that of his students in a graduate course, "Patterns of Environmentalism," at Antioch New England Graduate School, together with analysis of some of the actors and movements of American environmentalism since the 1800s. In each of six chapters, Thomashow focuses on a 
particular aspect of ecological identity, its connection to particular actors, movements, and approaches in environmentalism, and the EIW exercise(s) for exploring and developing this aspect in oneself.

Chapter One, "Voices of Ecological Identity," develops the concept of ecological identity, defined as the ways people construe themselves in relationship to the earth, as manifest in personality, values, actions, and sense of themselves (p.3). Thomashow's purpose is "to show how an ecological worldview can be used to interpret personal experience, and how that interpretation leads to new ways of understanding personal identity." This is ecological identity work. Through the creation and analysis of cluster diagrams, students explore their conceptions of environmentalism. Thomashow highlights the various "epistemological metaphors" (e.g., ecological consciousness, ecopsychology) identified in this analysis, and notes that each incorporates a connection between mind and ecosystem as a source of identity and action. Consideration of these metaphors is used to stimulate "critical reflection and deep introspection" (p.23) through which individuals widen "their circles of identification" to include nature and thereby enable them to internalize concern for its well-being as their own. This process also uncovers some of the tensions between ecological identity and environmental action, most notably that between one's desire for solitude in nature and a sense of responsibility to become involved in political action on its behalf.

Chapter Two, aptly entitled "Trees of Environmentalism (Environmentalism Evolving)," focuses on the evolution and diversification of American environmentalism. Thomashow considers Thoreau, Muir and Carson as the roots of the tree according to Thomashow, their various combinations of "practices of the wild," "natural history excursions," and "paths of citizenship" provide role models for integrating knowledge and personal values. The preservation-conservation debate and other controversies that constitute or play a role in environmental issues constitute the branches of the tree. (Thomashow's illustration using McPhee's Encounters with the Archdruid is a useful and refreshing example following the often repeated story of this debate's enactment by Muir and Roosevelt.) The leaves of the tree represent alternative approaches to environmentalism such as ecofeminism, deep ecology, and bioregionalism. As an exercise, the tree of environmentalism enables students to trace the evolution and expansion of American environmentalism. More importantly, it helps them discover the political and philosophical diversity among environmentalists, and the importance of "understanding history, appreciating positions, possibilities, and the historical and social context of environmental choices" (p.48). To complete the exercise, students must locate themselves on the tree, first according to their feelings, then as their professional persona would dictate. This often uncovers tensions they face in reconciling personal values and professional responsibilities.

In Chapter Three, "Ecological Identity and the Commons," Thomashow addresses the connection between individual identity and collective action through discussion of the commons, community, and ecological citizenship. He begins with a critical question: "When does identity lead to responsibility?" Although many who study common pool resources (CPRs) presume that the stronger one's economic, social, or cultural ties to the commons, the more likely one is to cooperate in its management and use, Thomashow does not take this as given. Rather, he explores the tensions between property and the commons, and between individualism and community, that must be addressed to make the connection between individual identity and responsibility for nature (i.e., the commons). He observes that we (in the U.S.) use (private) property to construct our personal identity. 
Because we tend not to identify with things that we do not own (e.g., nature), we are unlikely to recognize the larger consequences of that ownership for the commons. Moreover, this disconnection creates the possibility for controversies that are the heart of environmental politics. EIW challenges such narrow interpretations of property and selfidentity. But Thomashow reflects a similar narrowness of perspective in his assertion that the crucial problem of environmental politics is to develop approaches to the commons that maintain the sanctity of property rights, and that protect the individual but recognize ecosystem integrity (p.79).

Indeed, it is important to recognize peoples' attitudes, values and beliefs regarding private property and individual identity. But he seems to sidestep the problem; must (or should) we maintain the sanctity of private property rights? Nonetheless, the activity for exploring the commons dilemma is a constructive one: students do a complete inventory of their property, then seek to widen their circles of identification by considering the ecological, social, economic, and political processes that have contributed to their store of material goods. In so doing, they become more aware of the connection between their personal property and individual identity and, more importantly, the implications their acquisition, ownership, and use of various goods have for the commons. Reflection on the connection between their property and the commons establishes a "property/commons feedback network" that relates individual autonomy (in the possession of private goods) and collective responsibility (in one's own good and those connected to the commons), and thereby provides the rationale for personal action on behalf of the commons (although he does not point out the cumulative effect of individual actions, a key part of the commons problem).

Students' work on community network maps complements the property list in this stage of EIW. Students illustrate the structure of their relationships to others and their location within a community (or communities) as a foundation for discussion of what characteristics make for a cohesive, interdependent, and participatory community. This activity is important because it highlights our "pervasive culture of individualism, which seeks to separate the individual from the community" (p.89), and encourages consideration of communities' potential as a loci of political interaction and personal commitment, and the constraints to realizing that potential. In the concluding section of the chapter, Thomashow draws upon the work of Kemmis, Havel and Ostrom to develop a model and rationale for ecological citizenship. Kemmis' emphasis on the importance of public expression and consensus forged from diverse perspectives within communities, Havel's call for decentralization and local action with a moral foundation, and Ostrom's recognition that people can indeed manage the commons together suggest the opportunity and necessity for ecological citizenship.

In Chapter Four, "Political Identity and Ecological Citizenship," attention shifts from ecological to political identity, and how it can be enacted through ecological citizenship (i.e., environmental activism). The exercise for this purpose is the political autobiography through which students explore the flow(s) of power, how they approach power, and how they resolve the conflicts inherent in environmental issues. As part of this exercise, students address questions regarding the ethics of environmental activism and ecological citizenship. They consider their perceptions of human capabilities and behavior, how these relate to the various perspectives on the ability of liberal democratic institutions, and their broader views related to coercion versus democracy and administrative efficiency versus democratic process in addressing environmental problems. 
Chapter Five, "Ecological Identity and Healing," turns to the (often underestimated) psychospiritual impacts of the tensions that underlie environmental work and the psychological turmoil of global environmental change (p.148). These tensions are the source of anger and despair for many people, and have motivated many to seek out spiritual guidance for their efforts to enact an ecological worldview. Thomashow notes that the "great wisdom traditions" (it is not entirely clear what traditions in particular he is referring to; perhaps all religions, interpreted broadly) can offer guidance, as they address many questions and issues common to environmental work (e.g., living simply). Thus the work of the environmental practitioner, in promoting an ecological worldview and action consistent with it, "conveys a tone of moral judgment" (p.149). This can lead to cycles of blame and guilt, which can be paralyzing or, more beneficially, the catalyst for personal responsibility and action to heal the environment. To work through this challenge, Thomashow offers the "eco-confessional" in which he and his students discuss ecological wrongs they have committed. The goal of this activity is to encourage "reflective practice" (over and above that promoted thus far) as a mechanism for ongoing ecological healing of the self. This personal healing is a precursor to collective healing, and contributes to both "sustainable psyches and sustainable societies."

The last chapter, "Educating for Ecological Identity," lays out an EIW-based framework for teaching environmental studies and for promoting ecological literacy. The framework consists of three principles of educational design and nine "interpretive modalities." Neither the principles (highlight the importance of learners' experiences; establish open, cooperative learning spaces; provide conceptual vision) nor the modalities are particularly unusual (with the possible exception of the collaborative text). They do, however, remind us of the immense possibilities, beyond lectures and basic discussion, for teaching and learning. More valuable, perhaps, would have been a summary of the activities described in the text, which are both innovative and appropriate tools for teaching environmental studies, and other related courses as well at many levels. Thomashow then presents the culminating activity of EIW: the sense-of-place map. In this exercise, students express in writing, artwork, or other media the links between their own ecological identity and their life-cycle development. The particular value in this exercise is its reinforcement of the idea that sense of place is "literally the roots of ecological identity" (p.192), and its reflection on the range and variety of regions with which we might identify. Unfortunately, the exercise is not adequately described, nor are specific examples offered.

Thomashow closes the book with an Epilogue: "Ecological Identity as a Way of Saying Grace," in which the personalization and moralistic tone overwhelm. He asks how he can construct an ethical and moral foundation for his actions if he also accepts the temporality of interpretive meaning. For him, the answer lies in ecology's revelation of "patterns with lasting insight," and these patterns' consistency with the great wisdom traditions that have long provided spiritual guidance to people. Ecological identity work, then, as it comprises these cognitive and intuitive, practical and spiritual elements, is "a way of saying grace."

Although some may find the personalization and reflection of the epilogue consistent with the themes of the book, others will find it unnecessary, and somewhat overwhelming, if not arrogant. Two aspects of the book reinforce this conclusion. First, throughout the book, but especially in Chapter Five and the Epilogue, Thomashow suggests that an ecological worldview is the right worldview, and that those who promote that worldview are somehow morally superior to everyone else. He seems to suggest that those who work 
to convey this view are spiritual guides (or saviors) to the rest of us. One begins to feel as though they are to be martyrs as they struggle to do this work. Second, although Thomashow makes clear the limitation of his focus to the tradition of American environmentalism, and notes the possible difficulties of transferring the activities of EIW across cultures (p.180), he seems to avoid intercultural diversity (within the U.S. and more broadly) as it influences peoples beliefs, values, attitudes, and actions. Similarly, apart from ecological identity and identity with place, he largely ignores the multiplicity of identities people possess, and the fact that these identities take on greater or lesser salience in different situations.

These criticisms considered, Ecological Identity is appropriate for environmentalists seeking to strengthen their own ecological identity and to heal and fortify their psyches for the challenging work of environmental activism. And for the instructor of environmental studies, the activities he presents have great potential for use in the classroom, from gradeschool through graduate school. 